\title{
Toxocara spp. O INIMIGO QUE RONDA OS QUATRO CANTOS DO BRASIL
}

\author{
(Toxocara spp. an enemy that afflicts the four corners of Brazil)
}

Elizabeth Moreira dos Santos Schmidt ${ }^{1}$, Marcela Cristina de Cezaro

\begin{abstract}
${ }^{1}$ Correspondência: bethschmidt@fmvz.unesp.br
RESUMO: As espécies Toxocara canis e Toxocara cati são parasitos gastrintestinais de cães e gatos que apresentam distribuição mundial e são responsáveis pela zoonose conhecida como Toxocaríase, que acomete acidentalmente 0 homem, principalmente em países em desenvolvimento. No Brasil, o agente tem ampla distribuição, acometendo principalmente crianças, devido a hábitos geofágicos, contato íntimo com animais e acesso a caixas de areia contaminadas pelas fezes de cães e gatos em praças e parques de recreação. Observa-se a necessidade de transferir informações à população uma vez que esta importante infecção zoonótica está entre as mais comuns em todo o mundo e constitui-se em um risco potencial à saúde. Porém, ainda é muito negligenciada, seja pelo desconhecimento e/ou pela inespecificidade dos sinais clínicos e diagnóstico pouco solicitado rotineiramente. Devido à estreita relação entre o homem e seus animais de estimação que cresce constantemente, esta revisão objetivou investigar os fatores predisponentes, os sinais clínicos, os meios de diagnósticos disponíveis e a prevalência da infecção em cães, gatos, canídeos e felídeos selvagens e o homem, com base nos estudos retrospectivos feitos no Brasil.
\end{abstract}

Palavras-chave: larva migrans ocular; larva migrans visceral; saúde-pública

ABSTRACT: The species Toxocara canis and Toxocara cati are gastrointestinal parasites of dogs and cats that present worldwide distribution and are responsible for a zoonosis known as Toxocariasis, which accidentally afflicts humans, especially in developing countries. In Brazil, the agent is widely distributed, mostly affecting children, due to their geophagic habits, intimate contact with animals and access to sandboxes contaminated with canine and feline feces in recreational parks and squares. Information on this important zoonotic infection must be imparted to the population since it among the most common in the world and constitutes a potential health risk. However, it remains highly neglected due to ignorance and / or nonspecificity of clinical signs and rare solicitation of its diagnosis in routine care. Due to the growing closeness of the relationship between humans and their pets, this review aimed to investigate the predisposing factors, clinical signs, the available diagnostic means and prevalence of the infection in domestic and wild felines and canines, as well as humans, based on retrospective studies performed in Brazil.

Key Words: ocular larva migrans; visceral larva migrans; public health 


\section{INTRODUÇÃO}

O estreito contato entre humanos e seus animais de estimação cresce constantemente. A companhia oferecida pelos pets mostra muitos benefícios para a saúde mental e para o bem-estar físico do seu responsável, principalmente crianças, autistas e idosos (MACPHERSON, 2005). Porém, devido a este íntimo contato, deve-se atentar ao risco de transmissão de zoonoses, que podem por em risco a saúde humana e animal. Sabe-se que estes animais estão envolvidos em cerca de 60 infecções zoonóticas (MACPHERSON, 2012). Dentre as mais comuns, destaca-se a Toxocaríase, transmitida por cães e gatos, sendo Toxocara canis e Toxocara cati os seus respectivos agentes.

O homem contamina-se acidentalmente pela ingestão de ovos infectantes presentes no solo contaminado, na ingestão de saladas ou legumes mal lavados e ingestão de carne e/ou vísceras cruas ou mal cozidas contaminadas. O parasito migra por diversos órgãos causando reação inflamatória. Os sinais clínicos variam de assintomáticos a até casos graves dependendo da carga parasitária, órgãos afetados e resposta imunológica do hospedeiro (PAWLOWSKI, 2001). Com base nisso, estabeleceu-se a classificação da doença em quatro formas: Larva migrans visceral (LMV), Larva migrans ocular (LMO), oculta ou atípica e assintomática.

O homem e os animais domésticos estão cada vez mais próximos de áreas naturais, e com isso, a interação com os animais selvagens é cada vez maior. Diante da importância dos animais selvagens para o equilíbrio do ecossistema e o risco constante de extinção, observa-se que o potencial de transmissão e disseminação de doenças entre estes, os animais domésticos e o homem é considerado um problema. Com base nisso, um mapeamento dos relatos de parasitismo por Toxocara spp. em canídeos e felídeos selvagens também foi levantado nesta revisão.

A alta soroprevalência desta infecção no mundo bem como no Brasil, demonstra o grande problema de saúde pública causado por esse agente, principalmente em crianças, idosos, imunocomprometidos, habitantes de residências rurais e baixo estatus socioeconômico (RUBINSKY-ELEFANT et al., 2010). Desta forma, é crucial fornecer informações à população em relação ao agente, formas de contaminação, sinais clínicos, meios de diagnósticos disponíveis e, principalmente, formas profiláticas para evitar a infecção acidental. 
Toxocara spp. an enemy that afflicts the four corners of Brazil

\section{REVISÃO DA LITERATURA}

O agente causador desta zoonose é conhecido como Toxocara spp. pertencente ao Filo Nemathelmintes, Classe Nematoda, Ordem Ascaridida, Superfamília Ascaridoidea, Família Ascarididae, Subfamilia Toxocarinae, Gênero Toxocara, que possui 21 espécies (ANDERSON, 2000), destas, duas apresentam maior importância para a saúde pública: T. cati (WERNER, 1782) e T. cati (SHRANK, 1788). Diversos estudos apontam que $T$. cati é o principal responsável pela transmissão da Larva migrans visceral ao homem (SCHANTZ, 1989, QUEIRÓZ e CHIEFFI, 2005).

Os cães são os hospedeiros definitivos de $T$. cati, que parasita 0 intestino delgado destes animais. Possui ampla gama de hospedeiros paratênicos como: roedores, ovinos, bovinos, suínos, macacos e minhocas. É um parasito esbranquiçado e robusto. A fêmea pode medir até $18 \mathrm{~cm}$ e o macho até $10 \mathrm{~cm}$. A cabeça é eliptíca com asas cervicais, a boca circundada com três lábios e cápsula bucal ausente. $\mathrm{O}$ esôfago é desprovido de bulbo. A cauda do macho tem um apêndice estreito terminal e asas caudais (TAYLOR et al., 2010). Ovo é castanho escuro e subglobular, mede 90x70 $\mu \mathrm{m}$, com casca espessa rugosa formada por um revestimento proteico (GEORGI e GEORGI, 1992).

Os gatos são os hospedeiros definitivos de $T$. cati, que parasita $o$ intestino delgado desta espécie. Devido ao comportamento característico dos felinos como a caça, os roedores são considerados os principais hospedeiros paratênicos. Assim como T. cati, é um parasito esbranquiçado e possui asas cervicais proeminentes. A fêmea mede entre 4 a $10 \mathrm{~cm}$ e o macho 3 a $6 \mathrm{~cm}$. A cauda do macho apresenta um apêndice terminal estreito e um processo digitiforme na sua extremidade (TAYLOR et al., 2010). O ovo assemelha-se ao $T$. cati, porém é menor, com 55 - $75 \mu \mathrm{m}$ (GEORGI e GEORGI, 1992).

Os ovos eliminados nas fezes levam cerca de quatro semanas para tornarem-se infectantes no ambiente, apresentando-se larvados (L3), e quando ingeridos pelos seus hospedeiros definitivos, irão eclodir no intestino e liberar as L3 que irão invadir a mucosa intestinal e através do sistema porta chegarão ao fígado. Pela circulação alcançam o coração, pulmão, e regressam ao sistema digestório via traqueia e esôfago. Em aproximadamente cinco semanas o ciclo se completa e observa-se 0 
aparecimento de ovos nas fezes (OVERGAAUW e NEDERLAND, 1997). Esse ciclo habitual, também conhecido como "migração traqueal" comumente ocorre nos cães jovens (ANDERSON, 2000). Nos adultos, em geral, as larvas migram e se encistam nos tecidos do cão, caracterizando a "migração somática", que possui significativa importância na cadela gestante, devido a um mecanismo de reativação das larvas hipobióticas no terço final da gestação (DOUGLAS e BAKER, 1959).

A prolactina parece estar envolvida nesta reativação, pois possui efeito de supressão do sistema imune. Quando essas larvas migram para o útero gestante e atravessam a placenta, infectam os fetos. Alojam-se no pulmão fetal com aproximadamente 42 dias de gestação, caracterizando a contaminação transplacentária. Fêmeas gestantes podem infectar os seus filhotes por várias crias consecutivas. Os fetos nascem infectados e dentro de 12 a 15 dias, o parasito completa o ciclo pela "migração traqueal" e são observados ovos nos fezes do neonato (OVERGAAUW e NEDERLAND, 1997).

Outra forma de transmissão da cadela para sua prole é a transmamária. Fêmeas cronicamente infectadas ou que se contaminaram no final da gestação eliminam as larvas infectantes pelo leite.
Os filhotes infectados também são fonte de contaminação para suas mães, pois em infecções maciças podem eliminar nas fezes a larva de quinto estágio (L5), e a cadela, ao higienizá-lo, pode ingerir esta larva que irá se desenvolver em parasito adulto no intestino delgado. Em gatos, apesar de controverso, parece não haver infecção pré-natal, e a transmissão transmamária ocorre em infecções agudas no terço final da gestação. O período pré-patente é de oito semanas (WEESE e FULFORD, 2011). Por fim, outra forma de contaminação conhecida é pela ingestão do hospedeiro paratênico. Este pode ser um vertebrado ou invertebrado, e ao ingerir o ovo infectante presente no ambiente, sofrerá a migração somática, e, ao ser predado pelo hospedeiro definitivo, terá larvas no tecido que se tornam potencial fonte de contaminação (QUEIRÓZ e CHIEFFI, 2005) e quando ingeridas pelo cão ou gato, se desenvolvem em adultos no intestino delgado (OVERGAAUW e NEDERLAND, 1997). Além disso, essa parece ser uma via de infecção bastante importante para os animais selvagens (PARSONS, 1987).

No Brasil, observa-se que existe grande variação na prevalência da infecção em cães, sendo de $1 \%$ a $48,8 \%$ em exames coproparasitológicos 
e de $11,1 \%$ a $71,43 \%$ em necropsias (Tabela 1). Em gatos, 1,81\% a 19,1\% e $4,1 \%$ a $25,18 \%$, respectivamente (Tabela 2).

Cães adultos parecem adquirir imunidade e eliminar os parasitos adultos, mas os filhotes com menos de seis meses de idade são os grandes reservatórios do agente, devido à alta carga parasitária (QUEIRÓZ e CHIEFFI, 2005). Além disso, os cães que habitam áreas rurais parecem ser mais propensos à infecção (HABLUETZEL et al., 2003). As fêmeas parasitas são muito prolíferas podendo eliminar cerca de 200 mil ovos por dia (RUBINSKYELEFANT et al., 2010). Esses ovos apresentam grande resistência às condições adversas do meio ambiente, bem como a agentes químicos, podendo permanecer viáveis por muitos anos (OVERGAAUW e KNAPEN, 2013). Ademais, as cadelas possuem um papel epidemiológico importante constante, pois albergam as larvas nos tecidos, locais estes que a ação da maioria dos anti-helmínticos é dificultada, devido à presença do granuloma que engloba a larva, sendo assim, parece que apenas as larvas ativadas no final da gestação são susceptíveis aos anti-helmínticos (PARSONS, 1987).

A presença ou não de ovos nos pelos dos animais sempre foi algo muito discutido como um fator de risco. GILLIAN et al., (2007) avaliaram a pelagem de 100 cães errantes para a presença de ovos de Toxocara spp.. Encontraram $67 \%$ destes animais com ovos nos pelos, com uma recuperação média de 584 ovos por grama de pelo. Dos ovos recuperados, 95\% foram provenientes de filhotes. Logo, este fato se constitui em um risco potencial de transmissão de Toxocara spp..
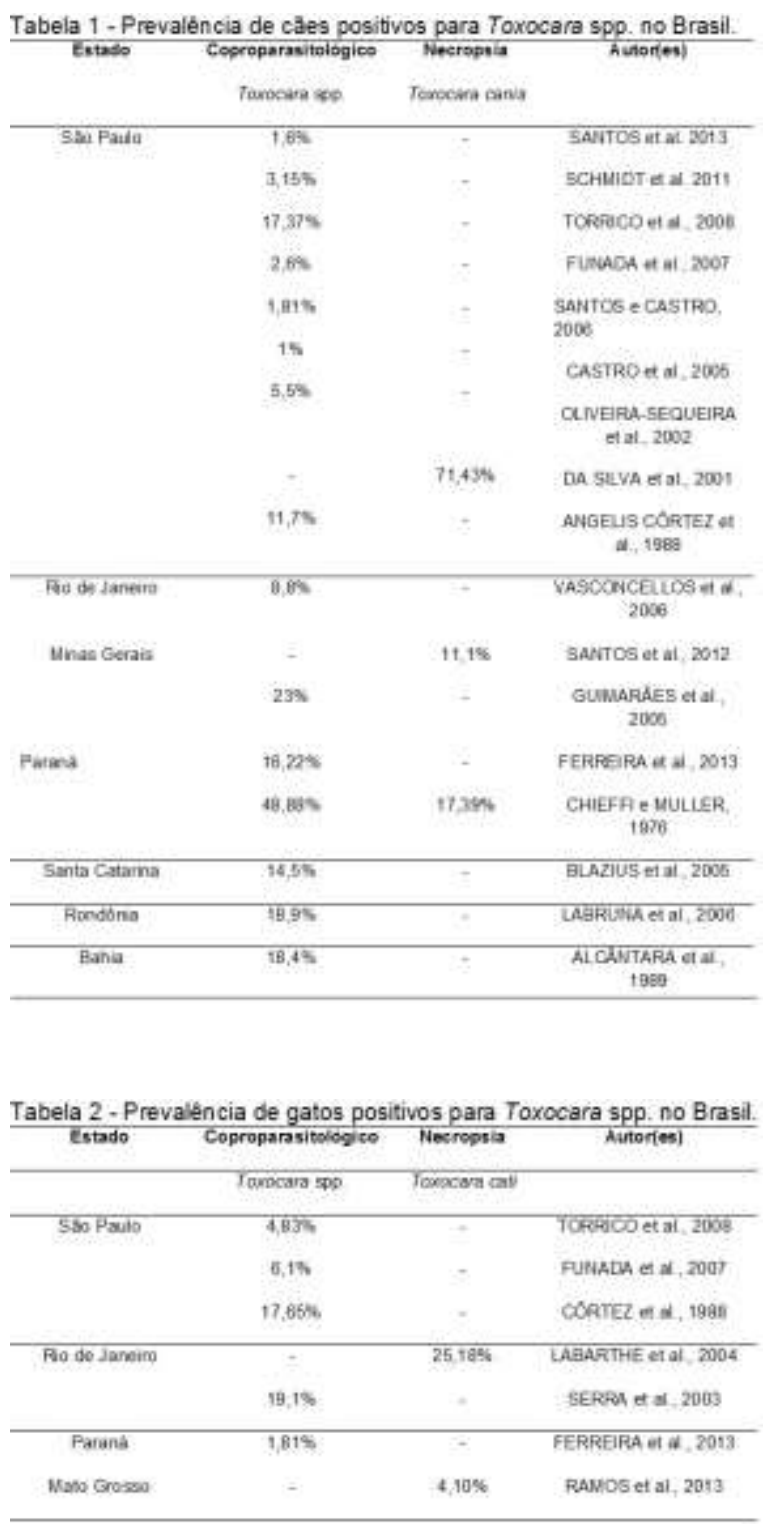
Assim como nos animais, em humanos a prevalência apresenta grande variação, entre $3 \%$ a $52 \%$, observada em avaliações sorológicas realizadas em alguns estados do Brasil (Tabela 3). Essa variação ocorre em decorrência da presença de alguns fatores predisponentes que podem facilitar a contaminação. As crianças apresentam grande risco devido a certos hábitos e comportamentos como: geofagia, apetite depravado, contato íntimo com animais e acesso aos parques e praças de recreação que contêm caixas de areia, uma vez que a contaminação ambiental pelos ovos de Toxocara spp. é muito comum (COLLI et al., 2010; CARVALHO e ROCHA, 2011).

Nos últimos anos os centros de educação infantil passaram a ser local de contaminação, pois as crianças os frequentam quando o sistema imunológico não está totalmente formado e ainda não há consciência sobre princípios básicos de higiene pessoal (QUADROS et al., 2004). FRIGHETTO et al., (2013) realizaram uma pesquisa de parasitos em chupetas de crianças de zero a cinco anos de idade, e encontraram uma prevalência de $7,14 \%$ para ovos de Toxocara spp. mostrando a importância da contaminação nesta idade. Hábitos culturais em que ocorre a ingestão de carne e/ou vísceras cruas ou mal cozidas de hospedeiros paratênicos também apresentam risco de infecção

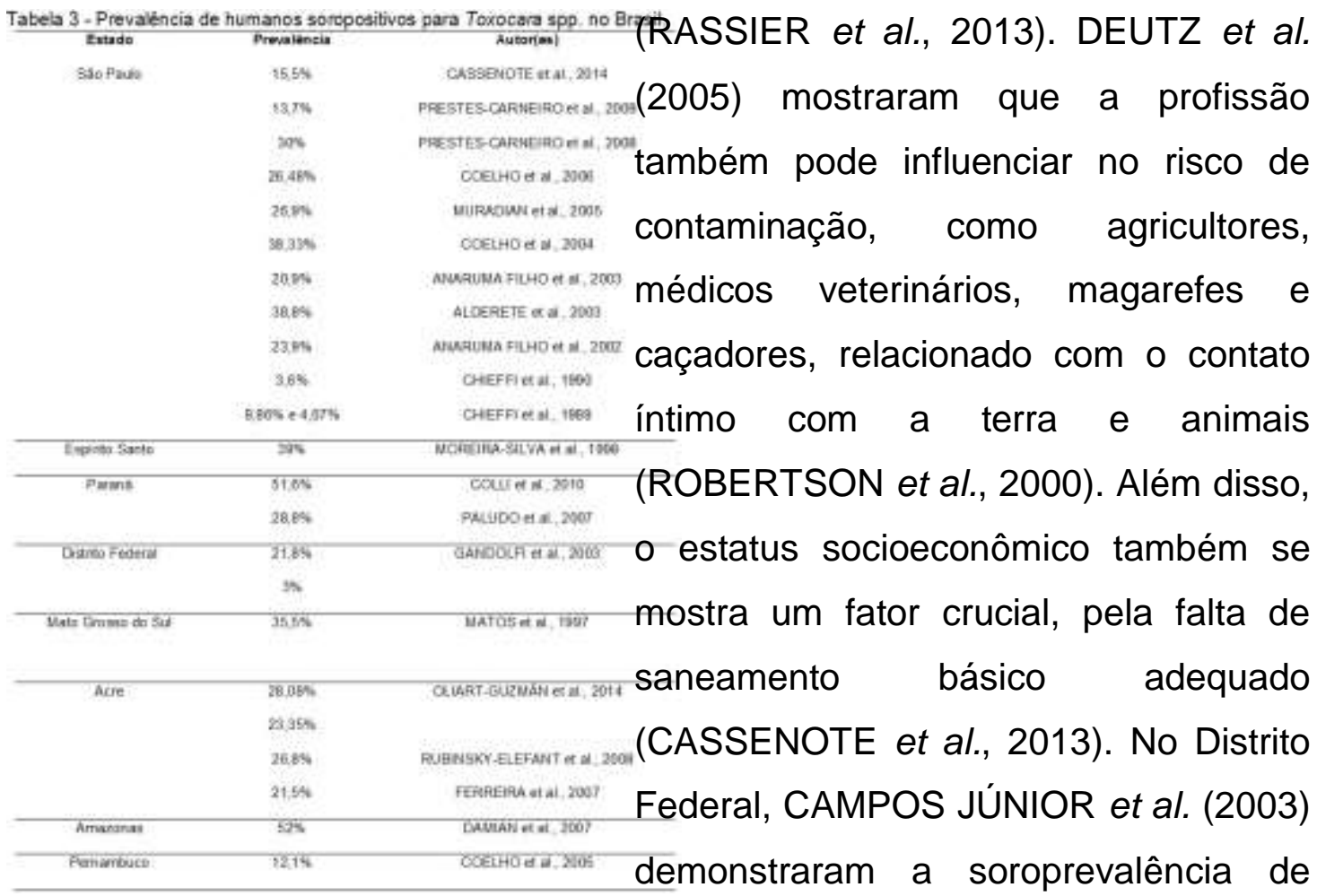


Toxocara spp. em crianças separadas em dois grupos com condições socioeconômicas distintas, avaliando amostras de laboratórios públicos e privados. Os resultados mostraram que as crianças dos bairros de baixa renda apresentaram $21,8 \%$ de soroprevalência para Toxocara spp. enquanto que as crianças de bairros de classe média, apenas $3 \%$.

No estado de São Paulo (Tabela 3), CHIEFFI et al. (1988) avaliaram o risco de infecção por Toxocara spp. em duas situações distintas, não relacionada ao sexo, mas sim, ao contato profissional e domiciliar com cães, em que os homens eram responsáveis pela captura de animais errantes das ruas e sua manutenção em canis, e as mulheres haviam tido ou tinham contato domiciliar com cães nos últimos dois anos. Os resultados mostraram que as mulheres apresentaram soroprevalência de 8,86\% e os homens $4,07 \%$, demostrando que ter animais em casa constitui-se em maior risco de contaminação do que a profissão. Possuir cão em casa também foi considerado fator de risco por ALDERETE et al. (2003) e COELHO et al. (2004).

Em uma investigação realizada por OLIART-GUZMÁN et al. (2014) foram avaliados os fatores de risco de crianças de zero a cinco anos de idade, no estado do Acre, sofrerem infecção por Toxocara spp. durante um período de sete anos. Em 2003, a soroprevalência foi de $28,08 \%$ e em 2010 de 23,03\%. Os autores comentaram que esse decréscimo pode ter ocorrido pela melhoria das condições socioeconômicas observadas ao longo dos anos, como por exemplo, melhora das moradias e acesso à água potável.

A Tabela 4 apresenta a prevalência de contaminação ambiental por Toxocara spp. em várias praças, parques e clubes de diferentes estados do país. No Brasil, observa-se que em várias cidades, cães e gatos circulam livremente por ruas e praças públicas. Tanto os cães e gatos errantes, como os domiciliados, guiados por seus donos, defecam nestas áreas e o não recolhimento das mesmas implica em um sério problema de saúde pública. Esses animais desempenham um papel epidemiológico importante como fonte para contaminação ambiental de parasitos, dentre eles o Toxocara spp., principalmente em áreas de recreação, constituindo em um risco eminente para as crianças (SCAINI et al., 2003). 


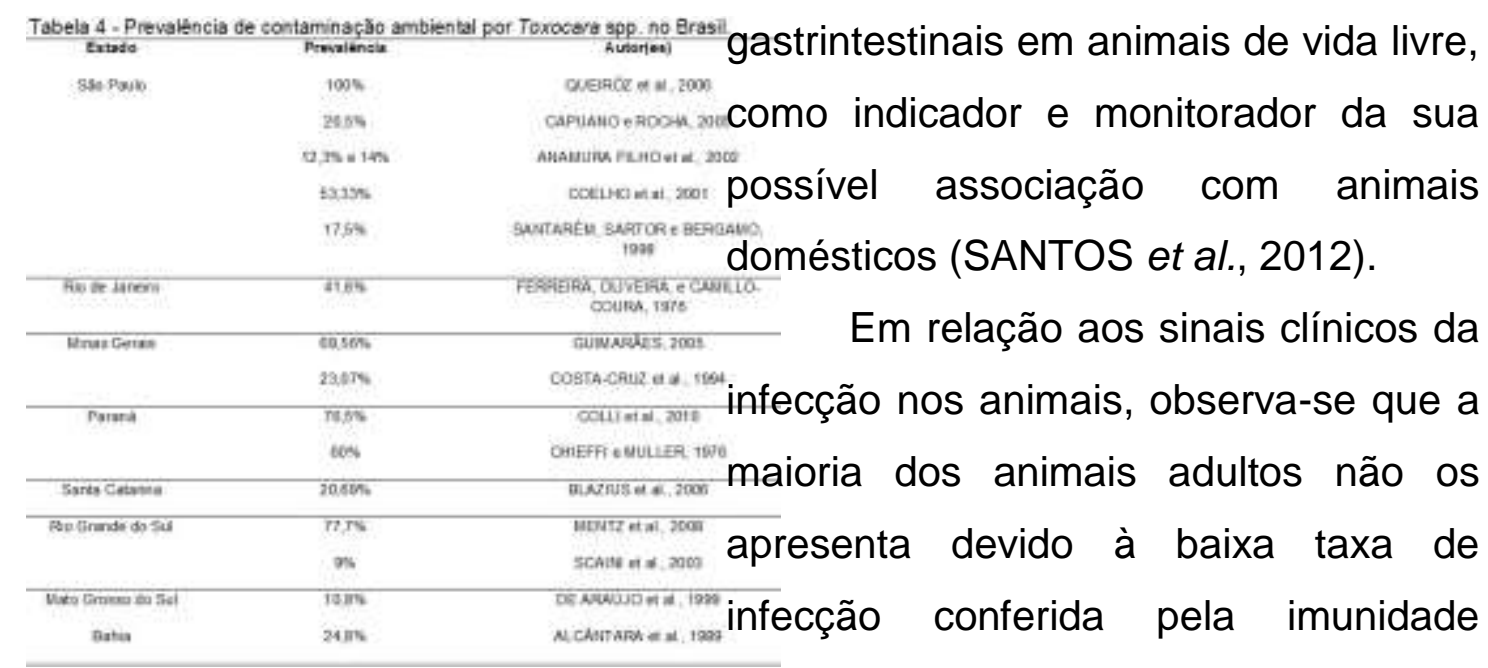

Nos últimos anos, como consequência do desmatamento devido ao avanço da agricultura e pecuária, bem como o crescimento das cidades, 0 homem e os animais domésticos estão cada vez mais próximos dos animais selvagens. Esse contato gera uma série de preocupações, pois facilita a disseminação de doenças e o surgimento de novas relações entre hospedeiros-parasitas. Logo, animais selvagens, assim como os domésticos, possuem papel epidemiológico importante na cadeia de transmissão de doenças (CÔRREA e PASSOS, 2001). $\mathrm{Na}$ Tabela 5, pode-se observar a ampla distribuição de Toxocara spp. em canídeos e felídeos selvagens no Brasil. Investigações relacionadas com a presença de helmintos nessas espécies selvagens ainda é recente e é um campo pouco explorado. Porém, destaca-se a importância da identificação de parasitas adquirida. Em filhotes, nas infecções maciças, ocorre o comprometimento da saúde e bem-estar animal. Os parasitos adultos no intestino podem causar abaulamento e distensão abdominal por formação de gás e até obstrução do lúmen do órgão com possível rompimento da víscera. Além disso, causam desconforto abdominal, enterite e constipação. $O$ animal pode apresentar vômito e diarreia ocasionais, inclusive com eliminação do parasito adulto. As fezes tendem a conter muco e, às vezes, vestígios de sangue. Pode haver manifestação de dor à palpação da região epigástrica (VOSSMANN, 1985). Observa-se falha no desenvolvimento, apatia, pelagem ruim e perda de peso. Os filhotes com infecção pré-natal podem apresentar grave comprometimento pulmonar, com tosse, secreção nasal e aumento da frequência respiratória, e o agravamento para pneumonia pode ser fatal (OVERGAAUW e NEDERLAND, 1997). 
No homem, atualmente, a toxocaríase é classificada em quatro formas: Larva migrans visceral (LMV), Larva migrans ocular (LMO), oculta ou atípica e assintomática. $\mathrm{Na}$ primeira forma, as larvas migram através dos principais órgãos, observa-se anemia, febre, hepatoesplenomegalia e manifestações pulmonares (tosse, dispneia, broncoespasmo). Pode ocorrer eosinofilia e hipergamaglobulinemia. Acomete principalmente crianças entre um e cinco anos de idade. Casos fatais podem ocorrer devido acometimento do miocárdio e do sistema nervoso central (QUEIRÓZ e CHIEFFI, 2005). Os sinais clínicos costumam perdurar por seis a 24 meses (BARRIGA, 1988).

Quantidades menores de larvas estão associadas à maior probabilidade de LMO do que LMV (GLICKMAN e SCHANTZ, 1981).

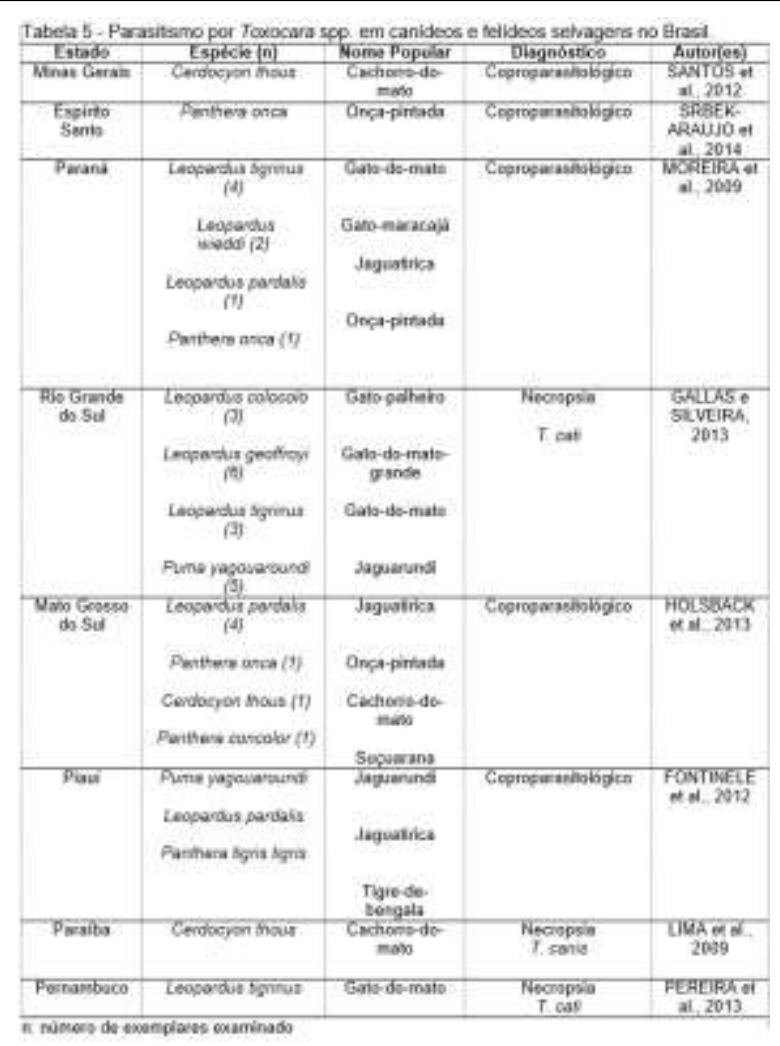

$\mathrm{Na}$ larva migrans ocular, há presença das larvas nos olhos ou nervo óptico, que se manifesta com a presença de granuloma retiniano, endoftalmite, catarata, ceratite e papilite óptica. $\mathrm{Na}$ maioria dos pacientes, observa-se apenas um único olho afetado (TAYLOR, 2001). Os sinais clínicos mais comuns são estrabismo, diminuição unilateral da visão, inflamação vítrea e leucocoria. Acomete principalmente crianças com mais de seis anos de idade. A forma oculta ou atípica acomete principalmente adultos e as manifestações clínicas são inespecíficas: dor abdominal recorrente, cefaleia, fraqueza, hepatomegalia e acometimento de outros órgãos, como por exemplo, os pulmões, levando a 
asma ou bronquite aguda ou a pele, caracterizado com urticária ou eczema (CARVALHO e ROCHA, 2011). O acometimento do sistema nervoso central pode estar associado a quadros de epilepsia, mudanças de comportamento, déficits cognitivos e podem ser um cofator para convulsões idiopáticas (WOODRUFF et al. 1966). Pode haver ausência de eosinofilia apesar de altos títulos sorológicos para Toxocara spp. (QUEIRÓZ e CHIEFFI, 2005). A invasão da larva termina em encapsulação no tecido, o que pode ser considerada uma reação que favorece a longa permanência e infectividade do parasita (BEAVER, 1969). Em geral, casos assintomáticos são decorrentes de infecções leves ou antigas (CARVALHO e ROCHA, 2011).

Em relação ao diagnóstico nos animais, os exames coproparasitológicos são utilizados para a pesquisa de ovos nas fezes, tais como métodos simples de flutuação como Willis-Mollay (1921), de centrífugoflutuação em sulfato de zinco $\left(\mathrm{ZnSO}_{4}\right)$ (FAUST et al., 1939), sedimentação simples (HOFFMANN, PONS e JANER, 1934) e método de centrífugosedimentação em água-éter (RITCHIE, 1948). Esfregaços fecais diretos com adição de uma gota de água também são úteis (TAYLOR et al., 2010).
O diagnóstico também pode ser feito pela observação do parasito adulto em vômito ou fezes dos animais (WEESE e FULFORD, 2011) ou como achados de necropsia (CHIEFFI e MULLER, 1976; LABARTHE et al., 2004; SANTOS et al., 2012; RAMOS et al., 2013). Os testes de ELISA e PCR são ferramentas úteis para a detecção da infecção, mas atualmente estão restritos a pesquisa (DANTAS-TORRES e OTRANTO, 2014; RUBEL et al., 2003).

Devido à inespecificidade dos sinais clínicos da doença no homem, se faz necessário recorrer a exames complementares. Quando se suspeita de toxocaríase deve-se primeiramente investigar o histórico do paciente, e avaliar os fatores de risco como: idade, hábitos, contato com animais, moradia, entre outros. Como as larvas de Toxocara spp. não completam o ciclo de vida no homem, não ocorre eliminação de ovos nas fezes, logo, exames coproparasitológicos não possuem aplicabilidade (RUBINSKY-ELEFANT et al., 2010). Para estabelecer 0 diagnóstico definitivo, devem-se encontrar larvas do parasito no exame histopatológico de tecido infectado. O fígado é o órgão de eleição para o procedimento, pois costuma ter maior acometimento do que em outros órgãos 
devido o sistema portal. A limitado, devido à baixa resposta imune

imunohistoquímica pode ser utilizada para identificação dos antígenos de $T$. cati no interior do granuloma, acelerando o diagnóstico (QUEIRÓZ e CHIEFFI, 2005). Devido a necessidade de buscar novas ferramentas diagnósticas, desde 1979 (DE SAVIGNY et al., 1979) o método de ELISA indireto vem sendo utilizado, com antígenos de excreção e secreção para T. cati (TES), apresentando boa sensibilidade e especificidade. O método Western blotting é altamente específico e pode ser usado para confirmar o ELISA. No entanto, o custo é mais elevado e é mais trabalhoso. A ocorrência de eosinofilia em resposta aos antígenos vem sendo relatada por muitos autores como um bom indicador de infecção e sua ausência pode ser devido a infecções leves ou antigas (CARVALHO e ROCHA, 2011). Elevação de IgE total sérica, isohemaglutininas anti-A e anti-B também podem ser importantes parâmetros para auxiliar o diagnóstico (EFEFANT et al., 2006).

A ultrassonografia pode ser utilizada para pesquisa de granulomas hipoecoicos hepáticos, sendo melhor do que a tomografia computadorizada devido à falta de nitidez da imagem (CARVALHO e ROCHA, 2011). O diagnóstico laboratorial da LMO é (ausência de eosinofilia), assim, baseiase nos sinais clínicos, ELISA com antígenos anti-Toxocara spp. no soro e fluído vítreo e exame de fundo de olho (QUEIRÓZ e CHIEFFI, 2005).

Quanto ao tratamento dos animais, como a maioria dos filhotes podem nascer infectados (GUILLAUME et al., 1991), deve-se realizar a primeira desverminação aos 15 dias de vida. $\mathrm{O}$ único princípio ativo seguro para os neonatos é o pamoato de pirantel. A associação de febantel $(15 \mathrm{mg} / \mathrm{kg})$ e pamoato de pirantel $(14,4 \mathrm{mg} / \mathrm{kg})$, e milbemicina oxima $(0,5 \mathrm{mg} / \mathrm{kg})$, é indicada para filhotes com mais de $500 \mathrm{~g}$ a partir de duas semanas de idade (SCHENKER et al., 2006). Posteriormente, tratar com quatro, seis e oito semanas de idade, devido ao risco do parasita estar sendo transmitido a partir do leite. Tratamentos mensais até os seis meses de vida mostram-se eficazes (ESCCAP, 2010). A desverminação mensal, uma a duas vezes por ano, ou pelo menos quatro vezes ao ano são recomendadas, porém, devem-se levar em consideração a condição de criação, número de animais contactantes, contato à rua e contato com potenciais indivíduos de risco. A partir do resultado de exame coproparasitológico e de 
medidas profiláticas, pode-se estabelecer o melhor protocolo de tratamento (WESSE e FULFORD, 2011).

Além do tratamento antihelmíntico, o emprego de medidas preventivas é de suma importância, como remoção das fezes, para diminuir a contaminação ambiental e limpeza das áreas em que as cadelas e seus filhotes ficam alojados. Para animais de áreas rurais, é importante evitar que estes sejam alimentados com vísceras ou carne crua e nos animais com hábitos de caça, evitar que tenham acesso a áreas de risco de ingestão de hospedeiros paratênicos (RASSIER et al., 2013).

Para o tratamento no homem, o princípio ativo de escolna é o albendazol, (DESPOMMIER, 2003). O uso de corticosteróides é empregado em casos de manifestações alérgicas agudas. Para a LMO recomenda-se albendazol (RUBINSKY-ELEFANT et al., 2010) ou procedimento cirúrgico para retirada da larva do parasita (vitrectomia ou laser) (DESPOMMIER, 2003).

A maioria dos casos de toxocaríase humana pode ser evitada, através de medidas simples e de educação, como melhoria de higiene, mudança de hábitos, supervisão da interação criança-animais, acesso à água potável e saneamento básico. $\mathrm{O}$ uso regular de anti-helmínticos também deve ser realizado. Gestantes e pessoas imunocomprometidas, devem ser mais vigilantes com seus animais de companhia, devido ao sistema imune mais frágil (ROBERTSON et al., 2000). Além disso, evitar sempre que possível o acesso de cães e gatos em locais de recreação para crianças, através de proteção com cercas e/ou telas e cobertura das caixas de areia, além de criar estratégias para fazer o controle populacional de animais errantes (MACPHERSON, 2005).

\section{CONCLUSÃO}

KATAGIRI e OLIVEIRASEQUEIRA (2008) revelaram que a maioria dos proprietários de cães desconhecem as espécies de parasitos intestinais, bem como os mecanismos de transmissão, fatores de risco de infecções zoonóticas e medidas preventivas e de controle para com eles, bem como com os animais. Além disso, com base nesta revisão foi possível observar dados sorológicos que demonstraram uma elevada exposição do homem ao Toxocara spp. Sendo, portanto, dever dos médicos veterinários orientar os proprietários quanto ao agente, transmissão, risco e importância 
de medidas preventivas, como 0 recolhimento das fezes dos cães, realização de exames coproparasitológicos e desverminação periódica, e também orientar os médicos para que considerem a toxocaríase como diagnóstico diferencial. De maneira geral, todos os profissionais envolvidos na saúde pública devem trabalhar juntos para alcançar o conceito de One World, One Health (OIE, 2014). Muito ainda precisa ser explorado quanto ao diagnóstico sorológico, em virtude da inespecificidade dos sinais clínicos da doença. Para o futuro, novas abordagens, como vacinas para cães, gatos $e$ iscas vacinais para os mamíferos selvagens que possam oferecer proteção ao longo da vida, podem ser ferramentas úteis para 0 controle da toxocaríase (DESPOMMIER, 2003).

Em linhas gerais, este levantamento de dados sobre 0 Toxocara spp. a partir de diferentes trabalhos realizados no Brasil, permitiu observar a importância deste parasitismo, pois está amplamente distribuído no território nacional, principalmente por se tratar de uma zoonose, e pela íntima relação do homem com seus animais de companhia, bem como o contato cada vez maior com os animais selvagens.
Apesar da riqueza de informações obtidas, pouco se sabe sobre a ocorrência deste parasito em muitas regiões brasileiras, assim, estudos futuros são cruciais para melhor conhecer e monitorar esta enfermidade.

\section{REFERÊNCIAS}

ALCÂNTARA, N.; BAVIA, E.; SILVÃO, R. M. Environmental contamination by Toxocara sp eggs in public areas of Salvador, Bahia State, Brazil. Revista da Sociedade Brasileira de Medicina Tropical, v. 22, n. 4, p. 187-190, 1989.

ALDERETE, J.; JACOB, C.; PASTORINO, A. C. et al. "Prevalence of Toxocara infection in schoolchildren from the Butantã region, São Paulo, Brazil." Memórias do Instituto Oswaldo Cruz 98.5. p. 593-597, 2003.

ANARUMA FILHO, F.; CHIEFFI, P. P.; CORREA, C. R. S. et al. "Human toxocariasis: a seroepidemiological survey in the municipality of Campinas (SP), Brazil." Revista do Instituto de Medicina Tropical de São Paulo" 44.6. p. 303-307, 2002.

ANARUMA FILHO, F.; CHIEFFI, P. P.; CORREA, C. R. S. et al. "Human toxocariasis: incidence among residents in the outskirts of Campinas, State of São Paulo, Brazil." Revista do Instituto de Medicina Tropical de São Paulo" 45.5. p. 293-294, 2003.

ANDERSON, R. C. Nematode parasites of vertebrates: their development and transmission. Cabi, p. 304-306, 2000.

ANGELIS CÔRTES, V.; PAIM, G. V.; ALENCAR FILHO, R. A. "Infestação por ancilostomídeos e toxocarídeos em cães e gatos apreendidos em vias públicas, São Paulo (Brasil)." Revista 
de Saúde Pública 22.4. p. 341-343, 1988.

ARAÚJO, F. R.; CROCCI, A. J.; RODRIGUES, R. G. C. et al. "Contaminação de praças públicas de Campo Grande, Mato Grosso do Sul, Brasil, por ovos de Toxocara e Ancylostoma em fezes de cães." Revista da Sociedade Brasileira de Medicina Tropical 32.5. p. 581-583, 1999.

BARRIGA, O. O. A critical look at the importance, prevalence and control of toxocariasis and the possibilities of immunological control. Veterinary parasitology, v. 29, n. 2, p. 195-234, 1988.

BEAVER, P. C. The nature of visceral larva migrans. Journal Parasitology. 55. p. 3-12, 1969.

BLAZIUS, R. D.; SILVA, O. S.; KAULING, A. L. et al. Contaminação da areia do Balneário de Laguna, SC, por Ancylostoma spp, e Toxocara spp em amostras fecais de cães e gatos. Arquivos Catarinenses de Medicina, v. 35, n. 3, p. 55-58, 2006.

BLAZIUS, R. D.; EMERICK, S.; PROPHIRO, J. S. et al. Ocorrência de protozoários e helmintos em amostras de fezes de cães errantes da cidade de Itapema, Santa Catarina. Rev Soc Bras Med Trop, v. 38, n. 1, p. 73-74, 2005.

BOWMAN, D. Parasitologia veterinária de Georgis. Elsevier Brasil, 9a Ed, p. 191-197, 2010.

CAMPOS JÚNIOR, D.; RUBINSKYELEFANT, G.; SILVA, E. O. M. et al. Freqüência de soropositividade para antígenos de Toxocara canis em crianças de classes sociais diferentes. Revista da Sociedade Brasileira de Medicina Tropical, v. 36, n. 4, p. 509513, 2003.
CAPUANO, D. M.; ROCHA, G. de M. Environmental contamination by Toxocara sp. eggs in Ribeirão Preto, São Paulo State, Brazil. Revista do Instituto de Medicina Tropical de São Paulo, v. 47, n. 4, p. 223-226, 2005.

CARVALHO, E. A. A.; ROCHA, R. L. Toxocariasis: visceral larva migrans in children. Jornal de pediatria, v. $87, \mathrm{n}$. 2, p. 100-110, 2011.

CASSENOTE, A. J. F.; ABREU DE LIMA, A. R.; NETO, J. M. P. et al. Seroprevalence and Modifiable Risk Factors for Toxocara spp. in Brazilian Schoolchildren. PLoS neglected tropical diseases, v. 8, n. 5, p. e2830, 2014

CASTRO, J. M.; SANTOS, S. V. D.; MONTEIRO, N. A. Contaminação de canteiros da orla marítima do Município de Praia Grande, São Paulo, por ovos de Ancylostoma e Toxocara em fezes de cães. Revista da Sociedade Brasileira de Medicina Tropical, v. 38, n. 2, p. 199-201, 2005.

CHIEFFI, P. P.; MÜLLER, E. E. Prevalência de parasitismo por Toxocara canis em cães e presença de ovos de Toxocara sp no solo de localidades públicas da zona urbana do município de Londrina, Estado do Paraná, Brasil. Revista de Saúde Pública, v. 10, n. 4, p. 367-372, 1976.

CHIEFFI, P. P.; UEDA, M.; CAMARGO, E. D. et al. Visceral larva migrans: a seroepidemiological survey in five municipalities of São Paulo State, Brazil. Revista do Instituto de Medicina Tropical de São Paulo, v. 32, n. 3, p. 204-210, 1990.

CHIEFFI, P. P.; UEDA, M.; CAMARGO, E. D. et al. "Contato domiciliar e profissional com cães como fatores de risco para infecção humana por larvas de Toxocara." Revista do Instituto de Medicina Tropical de São Paulo, v.30, n. 5, p. 379-382, 1988. 
COELHO, F. A. S.; ARAÚJO, A. J. U. S.; KANAMURA, $\mathrm{H}$. Y. et al. Frequency of anti-Toxocara sp antibodies and socioenvironmental characterization of a rural population in the city of Pindamonhangaba, SP, Brazil. Revista de Biociências (Taubaté), v. 12, p. 157-164, 2006.

COELHO, L. M. P.; DINI, C. Y.; MILMAN, M. H. D. S. A. et al. Toxocara spp. eggs in public squares of Sorocaba, São Paulo State, Brazil. Revista do Instituto de Medicina Tropical de São Paulo, v. 43, n. 4, p. 189-191, 2001.

COELHO, L. M. P. S.; SILVA, M. V.; DINI, C. Y. et al. Human toxocariasis: a seroepidemiological survey in schoolchildren of Sorocaba, Brazil. Memórias do Instituto Oswaldo Cruz, v. 99, n. 6, p. 533-557, 2004.

COÊLHO, R. A. L.; DE CARVALHO, L. B.; PEREZ, E. P. et al. Prevalence of toxocariasis in northeastern Brazil based on serology using recombinant Toxocara canis antigen. The American journal of tropical medicine and hygiene, v. 72, n. 1, p. 103-107, 2005.

COLLI, C. M. RUBINSKY-ELEFANT, G.; PALUDO, M. L. et al. Serological, clinical and epidemiological evaluation of toxocariasis in urban areas of south Brazil. Revista do Instituto de Medicina Tropical de São Paulo, v. 52, n. 2, p. 69-74, 2010.

CÔRREA, S. H. R.; PASSOS, E. C. Wild animals and public health. In: FOWLER M. E., CUBAS Z. S. Biology, medicine, and surgery of South American wild animals. Ames: lowa University Press. p. 493-499, 2001.

COSTA-CRUZ, J. M.; NUNES, R. S.; BUSO, A. G. et al. Presença de ovos de Toxocara spp. em praças públicas da cidade de Uberlândia, Minas Gerais, Brasil. Rev Inst Med Trop São Paulo, v. 36, p. 39-42, 1994.
DA SILVA, H. C.; CASTAGNOLLI, K. C.; DA SILVEIRA, D. M. et al. Fauna helmíntica de cães e gatos provenientes de alguns municípios do Estado de São Paulo. Semina: Ciências Agrárias, v. 22, n. 1, p. 67-71, 2001.

DAMIAN, M. M.; MARTINS, M.; SARDINHA, J. F. et al. Frequency of the antibody anti-Toxocara canis in a community along the Uatumã river, State of Amazonas. Revista da Sociedade Brasileira de Medicina Tropical, v. 40, n. 6, p. 661-664, 2007.

DANTAS-TORRES, F.; OTRANTO, D. Dogs, cats, parasites, and humans in Brazil: opening the black box. Parasit Vectors, v. 7, p. 22, 2014.

DE SAVIGNY, D. H.; VOLLER, A.; WOODRUFF, A. W. et al. Toxocariasis: serological diagnosis by enzyme immunoassay. Journal of Clinical Pathology, v. 32, n. 3, p. 284-288, 1979.

DESPOMMIER, D. Toxocariasis: clinical aspects, epidemiology, medical ecology, and molecular aspects. Clinical Microbiology Reviews, v. 16, n. 2, p. 265-272, 2003.

DEUTZ, A.; FUCHS, K.; AUER, H. et al. Toxocara-infestations in Austria: a study on the risk of infection of farmers, slaughterhouse staff, hunters and veterinarians. Parasitology research, v. 97, n. 5, p. 390-394, 2005.

ELEFANT, G. R.; SHIMIZU, S. H.; ARROYO SANCHEZ, M. C. et al. A serological follow-up of toxocariasis patients after chemotherapy based on the detection of $\lg G, \lg A$, and $\lg E$ antibodies by enzyme-linked immunosorbent assay. Journal of clinical laboratory analysis, v. 20, n. 4, p. 164-172, 2006.

ESCCAP (European Counsel for Companion Animal Parasites). Worm Control in Dogs and Cats Guideline 01, 2nd ed, p. 5-6, (www.esccap.org), 2010. 
FERREIRA, F. P.; DIAS, R. C. F.; MARTINS, T. A. et al. Frequência de parasitas gastrointestinais em cães e gatos do município de Londrina, PR, com enfoque em saúde pública. Semina: Ciências Agrárias, v. 34, n. 6Supl2, p. 3851-3858, 2013.

FERREIRA, L. F.; OLIVEIRA, E. L. D.; CAMILLO-COURA, L. et al. Sobre a presença de ovos de Toxocara em praças da cidade do Rio de Janeiro. Revista da Sociedade Brasileira de Medicina Tropical, v. 10, n. 2, p. 51-54, 1976.

FERREIRA, M. U.; RUBINSKYELEFANT, G.; DE CASTRO, T. G. et al. Bottle feeding and exposure to Toxocara as risk factors for wheezing illness among under-five Amazonian children: a population-based cross-sectional study. Journal of tropical pediatrics, v. 53, n. 2, p. 119-124, 2007.

FRIGHETTO, M.; DAMBRÓS, B.; BARREMAKER, $V$. Ocorrência de parasitos em chupetas de crianças em um centro municipal de educação infantil do município de videira, SC. Unoesc \& Ciência-ACBS, v. 4, n. 2, p. 177-186, 2013.

FONTINELE, C.; RODRIGUES, V.; ANDRADE, E. et al. Levantamento de endoparasitoses de felídeos do parque zoobotânico de Teresina-Piauí. Archives of Veterinary Science, v. 17, 2012.

FUNADA, M. R.; PENA, H. F. J.; SOARES, R. M. et al. Freqüência de parasitos gastrintestinais em cães e gatos atendidos em hospital-escola veterinário da cidade de São Paulo. Arq. Bras. Med, v. 59, n. 5, p. 13381340, 2007.

GALLAS, M.; DA SILVEIRA, E. F. Toxocara cati (Nematoda, Ascarididae) in different wild feline species in Brazil: new host records. Biotemas, v. 26, n. 3, p. 117-125, 2013.

GEORGI, J. R.; GEORGI, M. E. Canine clinical parasitology. Lea \& Febiger, p. 170-174, 1991.

GUILLAUME, G.; CARLIER, Y.; LOSSON, B. et al. L'hyper-éosinophilie chronique asymptomatique. A propos d'un cas de toxocarose professionnelle.

Revue médicale de Bruxelles, v. 12, n. 6, p. 209-214, 1991.

GUIMARÃES, A. M.; ALVES, E. G. L.; REZENDE, G. F. et al. Ovos de Toxocara sp. e larvas de Ancylostoma sp. em praça pública de Lavras, MG. Rev Saúde Pública, v. 39, n. 2, p. 2935, 2005.

HABLUETZEL, A.; TRALDI, G.; RUGGIERI, S. et al. An estimation of Toxocara canis prevalence in dogs, environmental egg contamination and risk of human infection in the Marche region of Italy. Veterinary Parasitology, v. 113, n. 3, p. 243-252, 2003.

HOFFMANN, R.P. Diagnóstico de parasitismo veterinário. Porto Alegre: Sulina; p. 33-43, 1987.

HOLSBACK, L.; CARDOSO, M. J. L.; FAGNANI, R. et al. Natural infection by endoparasites among free-living wild animals. Revista Brasileira de Parasitologia Veterinária, v. 22, n. 2, p. 302-306, 2013.

http://www.oie.int/for-the-

media/editorials/detail/article/one-worldone-health/ visitado em 12/11/2014.

KATAGIRI, S.; OLIVEIRA-SEQUEIRA, T. C. G. Prevalence of dog intestinal parasites and risk perception of zoonotic infection by dog owners in São Paulo State, Brazil. Zoonoses and public health, v. 55, n. 8-10, p. 406-413, 2008.

LABARTHE, N.; SERRÃO, M. L.; FERREIRA, A. M. R. et al. A survey of gastrointestinal helminths in cats of the metropolitan region of Rio de Janeiro, 
Brazil. Veterinary parasitology, v. 123, n. 1, p. 133-139, 2004.

LABRUNA, M. B.; PENA, H. F. J.; SOUZA, S. L. P. et al. Prevalência de endoparasitas em cães da área urbana do município de Monte Negro, Rondônia. Arquivos do Instituto Biológico, v. 73, n. 2, p. 183-193, 2006.

LIMA, R. C. A. Helmintos gastrintestinais de Cerdocyon thous (Linnaeus, 1766) Smith, 1839 provenientes da área de caatinga do estado da Paraíba, Brasil. 2009.

MACPHERSON, C. N. L. Human behaviour and the epidemiology of parasitic zoonoses. International journal for parasitology, v. 35, n. 11, p. 1319-1331, 2005.

MACPHERSON, C. N. L. Dogs, zoonoses and public health. CABI, 2012.

MATOS, M. de F. C.; MILITÃO, D. N. A.; BRUM, M. A. R. et al. Presence of antiToxocara antibodies in children selected at Hospital Universitário, Campo Grande, MS, Brazil. Revista do Instituto de Medicina Tropical de São Paulo, v. 39, p. 49-50, 1997.

MENTZ, M. B.; ROTT, M. B.; JACOBSEN, S. I. V. et al. Freqüência de ovos de Toxocara spp. em três parques públicos da cidade de Porto Alegre, Rio Grande do Sul, Brasil. Revista de Patologia Tropical, v. 33, n. 1, 2008.

MOREIRA, L. H. de A.; YAMADA, F. H.; CESCHINI, T. L. et al. Study of the gastrointestinal parasites in felines from Itaipu Binacional wild animal nursery, Brazil. Arquivos de Ciências Veterinárias e Zoologia da UNIPAR, $v$. 12, n. 1, p. 11-15, 2009.

MOREIRA-SILVA, S. F.; LEÃO, M. E.; MENDONÇA, H. F. et al. Prevalence of anti-Toxocara antibodies in a random sample of inpatients at a children's hospital in Vitória, Espírito Santo, Brazil. Revista do Instituto de Medicina
Tropical de São Paulo, v. 40, n. 4, p. 263-264, 1998.

MURADIAN, V.; GENNARI, S. M.; GLICKMAN, L. T. et al. Epidemiological aspects of visceral larva migrans in children living at Sao Remo Community, Sao Paulo (SP), Brazil. Veterinary parasitology, v. 134, n. 1, p. 93-97, 2005.

OLIART-GUZMÁN, H.; DELFINO, B. M.; MARTINS, A. C. et al. Epidemiology and Control of Child Toxocariasis in the Western Brazilian Amazon-A Population-Based Study. The American journal of tropical medicine and hygiene, v. 90, n. 4, p. 670-681, 2014.

OLIVEIRA-SEQUEIRA, T. C. G.; AMARANTE, A. F. T.; FERRARI, T. B. et al. Prevalence of intestinal parasites in dogs from São Paulo State, Brazil. Veterinary Parasitology, v. 103, n. 1, p. 19-27, 2002.

OVERGAAUW, P. A. M.; VAN KNAPEN, $F$. Veterinary and public health aspects of Toxocara spp. Veterinary parasitology, v. 193 , n. 4 , p. $398-403$, 2013.

OVERGAAUW, P. A. M.; NEDERLAND, V. Aspects of Toxocara epidemiology: human toxocarosis. Critical reviews in microbiology, v. 23 , n. 3 , p. 215-231, 1997.

PALUDO, M. L.; FALAVIGNA, D. L. M.; ELEFANT, G. R. et al. Frequency of Toxocara infection in children attended by the health public service of Maringá, south Brazil. Revista do Instituto de Medicina Tropical de São Paulo, v. 49, n. 6, p. 343-348, 2007.

PARSONS, J. C. Ascarid infections of cats and dogs. The Veterinary clinics of North America. Small animal practice, v. 17 , n. 6 , p. 1307-1339, 1987.

PAWLOWSKI, Z. Toxocariasis in humans: clinical expression and treatment dilemma. Journal of 
helminthology, v. 75 , n. 04 , p. 299-305, 2001.

PEREIRA, M. F.; OLIVEIRA, J. B.; SANTOS, F. L. et al. Toxocara cati em jaguatirica (leopardus tigrinus)-relato de caso. Archives of Veterinary Science, v. 18, n. 3, 2013.

PRESTES-CARNEIRO, L. E.; SANTARÉM, V.; ZAGO, S. C. S. et al. Sero-epidemiology of toxocariasis in a rural settlement in São Paulo state, Brazil. Annals of tropical medicine and parasitology, v. 102, n. 4, p. 347356, 2008.

PRESTES-CARNEIRO, L. E.; SOUZA, D. H. P.; MORENO, G. C. et al. Toxocariasis/cysticercosis

seroprevalence in a long-term rural settlement, São Paulo, Brazil. Parasitology, v. 136 , n. 06 , p. 681-689, 2009.

QUADROS, M. R. MARQUES, S.; ARRUDAL, R. et al. Parasitas intestinais em centros de educação infantil municipal de Lages, SC, Brasil. Rev. Soc. Bras. Med. Trop, Uberaba, v. 37, n. 5, p. 422-423, 2004.

QUEIRÓZ, M. L.; CHIEFFI, P. P. Síndrome de Larva migrans visceral e Toxocara canis. Arquivos médicos dos hospitais e da Faculdade de Ciências médicas Santa Casa de São Paulo 50(3):1. 17-120, 2005.

QUEIRÓZ, M. L.; SIMONSEN, M.; PASCOALOTTI, M. A. et al. Frequency of soil contamination by Toxocara canis eggs in the south region of São Paulo municipality (SP, Brazil) in a 18 month period. Revista do Instituto de Medicina Tropical de São Paulo, v. 48, n. 6, p. 317-319, 2006.

RAMOS, D. G. S.; SCHEREMETA, R. G. A. D. C.; OLIVEIRA, A. C. S. D. et al. Survey of helminth parasites of cats from the metropolitan area of Cuiabá, Mato Grosso, Brazil. Revista Brasileira de Parasitologia Veterinária, v. 22, n. 2, p. 201-206, 2013.

RASSIER, G. L.; BORSUK, S.; PAPPEN, F. et al. Toxocara spp. seroprevalence in sheep from southern Brazil. Parasitology research, v. 112, n. 9, p. 3181-3186, 2013.

ROBERTSON, I. D.; IRWIN, P. J.; LYMBERY, A. J. et al. The role of companion animals in the emergence of parasitic zoonoses. International journal for parasitology, v. 30, n. 12, p. 1369-1377, 2000.

RUBEL, D.; ZUNINO, G.; SANTILLÁN, G. et al. Epidemiology of Toxocara canis in the dog population from two areas of different socioeconomic status, Greater Buenos Aires, Argentina. Veterinary parasitology, v. 115 , n. 3 , p. 275-286, 2003.

RUBINSKY-ELEFANT, G.; SILVANUNES, M.; MALAFRONTE, R. S. et al. Human toxocariasis in rural Brazilian Amazonia: seroprevalence, risk factors, and spatial distribution. The American journal of tropical medicine and hygiene, v. 79, n. 1, p. 93-98, 2008.

RUBINSKY-ELEFANT, G.; HIRATA, C. E.; YAMAMOTO, J. H. et al. Human toxocariasis: diagnosis, worldwide seroprevalences and clinical expression of the systemic and ocular forms. Annals of tropical medicine and parasitology, v. 104, n. 1, p. 3-23, 2010.

SANTARÉM, V. A.; SARTOR, I. F.; BERGAMO, F. M. M. et al. Contaminação, por ovos de Toxocara spp, de parques e praças públicas de Botucatu, São Paulo, Brasil. Revista da Sociedade Brasileira Medicina Tropical, v. 31, n. 6, p. 529-32, 1998.

SANTOS, G. J.; SCHMIDT, E. M. S.; LIMA, A.F.M. Ocorrência de parasitismo gastrintestinal em cães oriundos de um programa populacional no Estado de São Paulo. In: $40^{\circ}$ Congresso Brasileiro 
de Medicina Veterinária, Salvador, BA, p. 05, 2013.

SANTOS, J. L. C.; MAGALHÃES, N. B.; SANTOS, $H$. A. et al. Parasites of domestic and wild canids in the region of Serra do Cipó National Park, Brazil. Revista Brasileira de Parasitologia Veterinária, v. 21, n. 3, p. 270-277, 2012

SANTOS, S. V.; DE CASTRO, J. M. Ocorrência de agentes parasitários com potencial zoonótico de transmissão em fezes de cães domiciliados do município de Guarulhos, SP. Arquivos Instituto Biológico, São Paulo, v. 73, n. 2, p. 255-257, 2006.

SCAINI, C. J.; TOLEDO, R. N.; LOVATEL, R. et al. Contaminação ambiental por ovos e larvas de helmintos em fezes de cães na área central do Balneário Cassino, Rio Grande do Sul. Revista da Sociedade Brasileira de Medicina Tropical, v. 36, n. 5, p. 617-619, 2003.

SCHANTZ, P. M. Toxocara larva migrans now. The American journal of tropical medicine and hygiene, v. 41, n. 3 Part 2, p. 21-34, 1989.

SCHENKER, R. CODY, R.; STREHLAU, $G$. et al. Comparative effects of milbemycin oxime-based and febantelpyrantel embonate-based anthelmintic tablets on Toxocara canis egg shedding in naturally infected pups. Veterinary parasitology, v. 137, n. 3 , p. 369-373, 2006.

SCHMIDT, E. M. S.; LIMA, A.F.M.; SALVADOR, M.C. et al. Frequência de parasitos intestinais em cães castrados em projeto de controle populacional no município de Botucatu-SP. In: Anais $5^{\circ}$ Congresso Brasileiro de Extensão Universitária, Porto Alegre, RS, p. 1216, 2011.

SERRA, C. M.; UCHÔA, C. M. A.; COIMBRA, R. A. et al. Exame parasitológico de fezes de gatos (Felis catus domesticus) domiciliados e errantes da Região Metropolitana do Rio de Janeiro, Brasil. Revista da Sociedade Brasileira de Medicina Tropical, v. 36, n. 3, p. 331-334, 2003.

SRBEK-ARAUJO, A. C.; SANTOS, J. L. C.; ALMEIDA, V. M. et al. First record of intestinal parasites in a wild population of jaguar in the Brazilian Atlantic Forest. Revista Brasileira de Parasitologia Veterinária, v. 23, n. 3, p. 393-398, 2014.

TAYLOR, M. A.; Coop, R. L.; Wall, R. L. Parasitologia Veterinária, 3a edição, p. $304-307,2010$.

TAYLOR, M. R. H. The epidemiology of ocular toxocariasis. Journal of helminthology, v. 75 , n. 02, p. 109-118, 2001.

TORRICO, K. J.; SANTOS, K. R.; MARTINS, T. et al. Ocorrência de parasitas gastrintestinais em cães e gatos na rotina do laboratório de enfermidades parasitárias da FMVZ/UNESP-Botucatu, SP. Revista Brasileira de Parasitologia Veterinária, p. 182-183, 2008.

VASCONCELLOS, M. C.; DE BARROS, J. S. L.; OLIVEIRA, C. S. Parasitas gastrointestinais em cães institucionalizados no Rio de Janeiro, RJ. Revista de Saúde Pública, v. 40, n. 2, p. 321-323, 2006.

VOSSMANN, M. T. Klinische, hamatogolische und serologische Befunde bei Welpen nach pranater Infektion mit Toxocara canis Werner 1789 (sic!) (Anisakidae). DMV Thesis. Hannover, 1985.

WEESE, J. S.; FULFORD, M. B. Companion animal zoonoses. WileyBlackwell, p. 59 - 69, 2011.

WOODRUFF, A. W.; BISSERU, B.; BOWE, J. C. Infection with animal helminths as a factor in causing poliomyelitis and epilepsy. British medical journal, v. 1, n. 5503, p. 1576, 1966. 